\title{
An Analysis Study of Factors That Determine E-Services Usage by End Users: A Case Study
}

\author{
Emad Bataineh $^{1}$ and Sara Al Mutawa ${ }^{2}$ \\ ${ }^{1}$ Zayed University, Dubai, UAE \\ ${ }^{2}$ General Directorate of Residency and Foreigners Affairs, Dubai \\ Correspondence should be addressed to: Emad Bataineh; Emad.Bataineh@zu.ac.ae
}

Received date: 12 August 2015; Accepted date: 14 September 2015; published date: 21 June 2016

Academic Editor: Mohamed Noureldin Ahmed Abdelhakim

Copyright $@$ 2016. Emad Bataineh and Sara Al Mutawa . Distributed under Creative Commons CC-BY 4.0

\begin{abstract}
The primary focus of this study is to investigate and identify the perceptions of potential end users relating to factors which impact on e-services acceptance. Technology Acceptance Model (TAM) has been adopted in this study as it can be extended when technologies are introduced. This research validates the developed TAM model and evaluates the variance of the outcome variable (acceptance of e-services). Five factors were adopted as determinants of acceptance of e-services: ease of use, security, trust, web skills, and language. The study was undertaken in the General Directorate of Residency and Foreigners Affairs (GDRFA) in the UAE. A quantitative survey methodology was adopted in this study, which surveyed 466 customers who use the GDRFA e-services. The overall findings revealed that security language, web skills and support significantly affected ease of use and perceived usefulness. However, trust does not affect ease of use. Further, ease of use significantly affects intention to use and perceived usefulness while in turn intention to use was influenced by perceived usefulness. This study offers an understanding of people's adoption of e-government services with the help of established theories such as TAM and various factors that influence the e-government adoption with reference to UAE.
\end{abstract}

Keywords: e-Government portal, e-service, usability, TAM model, Customer acceptance

\section{Introduction}

The last decade of the $20^{\text {th }}$ century was marked by the emergence of the Internet and its widespread use. E-services are a modular and rapid model of services that can be provided to both customers and other businesses through electronic means such as the Internet. Any kind of business service can be converted into an e-service 
to provide a much faster and more efficient service. A future modern and successful welfare state will require most of its public services and government administrations to be digitized utilizing E-services (Zhao et al., 2012). In combination with the rapid technological advancements in research, together with the wide spread use and adoption of such technologies will lead many governments to look favorably at developing and utilizing E-services within their government (Reddick, 2006). Egovernment refers to information technology and its use towards creating a better, faster and more transparent window through which the government operates and offers its services to the people (Yildiz, 2007). E-government provides an effective medium for citizens and other stakeholders to exchange information from their government, as well as execute essential tasks such as filing their tax returns and payment of government bills such as electricity/gas etc. E-government platform has the potential to make the government more transparent, visible and effective. Many government agencies have started to utilize e-services so as to deliver different services to the community in an appropriate manner, however the functions and benefits of e-services are not yet comprehensively explored (Ghosh, 2009).

The state of e-government adoption in the Gulf Corporation countries is still at an immature state despite various efforts taken by the government to propagate the importance of e-services. At present, the studies have not paid enough attention to examining the factors that may impact the adoption of e-services. The study investigates the factors associated with adopting e-government services in one of the Middle-Eastern countries, the result of which can be extrapolated to the other Middle East countries.

The main focus of this study is to identify the perception of ultimate users of egovernment services as well as to denote specific factors hindering the egovernment usage by government sectors. E-government needs to meet the general and specific needs of its users and to allow for the development of online services which would meet the expectation of all users. The intention should not just be to replicate the manual service but to go much further in enhancing the services that customers can receive through egovernment. E-government needs a citizencentric approach, following a step-by-step process wherein the marketing basics can be utilized to maximum advantage. Even though the use of e-services provides a convenient and efficient access to electronic services, a little is understood about how consumers evaluate its acceptance (Featherman and Pavlou, 2003). Most prior studies have been undertaken in developed countries. This research investigates and identifies key factors that impact the acceptance of eservices in the United Arab Emirates (UAE). This study provides clarity to issues relating to acceptance by the public sector. The study adopted Technology Acceptance Model (TAM) in comparison to other adoption models such as Theory of Planned Behavior (TPB) and Theory of Reasoned Action (TRA).

This study will consider the issues and concerns associated with the successful acceptance of e-services in the government sector in the United Arab Emirates (UAE) using TAM as a base model. E-Government service development is still in its early stages in the UAE and government services departments such as the Ministry of Interior, Ministry of Labour, Ministry of Health, Ministry of Higher Education, and Ministry of Treasury. All of these ministries offer e-services to users through departments and centres that have been established for this purpose. The Ministry of Interior is considered to be one of the pioneers in the introduction and implementation of e-services. The GDRFA department is a crucial part of the Ministry of Interior in the UAE due to the essential and critical activities conducted by this department. There is a variety of services offered by GDRFA Department through eservices such as renewal of the entry permit, e-gate card for the citizens of UAE, the issuing of passports and the provision of substitute passports that have been lost, and payment of fines imposed upon 
defiance of immigration regulations. There are seven departments of GDRFA working in the UAE, all of which provide users with e-services particularly to the UAE Citizens, Residents, Gulf Cooperation Council National (UAE, Bahrain, Qatar, Oman, Kuwait and Saudi Arabia) and Visitors.

The paper is organized as follows: the first section discusses the research questions and objectives. The second section presents and discusses the literature and related work including TAM, Dubai eservices modules and e-services using TAM. The third section explains the methodology used in the research. The subsequent section presents the summary of the main findings, data analysis and discussion of results. The last section contains the conclusion which includes a summary, implications and recommendations, limitations and suggestions for future research.

\section{Research Questions and Objectives}

Lately, there is an increasing demand for the presence of interactive web applications to facilitate ease of use for the citizens of the UAE. The increase in transparency, two way communication and interactions of the government with citizens and businesses, has become a vital part of any governance. Therefore egovernance measures require the presence of such Interactive Web application, which enables the increase in participation of citizens and awareness toward the benefits of these applications. In the United Arab Emirates, the government is investing significant funds for its e-services; but there are still low levels of acceptance in using such services. This research uses the Technology Acceptance Model approach in order to identify the significant issues among the wide range of factors stated in the literature.

The study is designed to address two major research questions:

1) What are the significant factors perceived by end users that impact on the successful acceptance of e-services in one agency in the public sector in the UAE?

2) Is the developed model valid and reliable to measure and evaluate the variance of the outcome variable (acceptance of e-services)?

Considering that the TAM model has been tested widely in developed countries, the answer to the second question will provide an answer to the question of the validity and reliability of the model in developing counties such as the UAE (or in different cultural environments).

E-services are usually more convenient to use, although it is still not fully known how inclined consumers are towards acceptance of e-services (Featherman and Pavlou, 2003). The significance of this study is its attempt to identify the factors that are perceived to influence the successful acceptance of e-services. Different dimensions will be considered in the study model. Education and experience have been selected as essential factors that affect acceptance. This construct includes factors which deal with how users perceive the use of online services according to cultural norms and values. The behavior of consumers in using e-services will also be examined. Significant recommendations will be provided to make an informed management decision for future planning as well as the development of government initiatives within the UAE. As the UAE government acts as a role model for the other Gulf Cooperation Council as well as other developing countries, this research will act as a model for e-government implications and it will directly support and guide the transformation to egovernment from the federal government.

\section{Related Work}

There are several definitions underlying the concept of e- government based on the views and opinions by many experts as most of them propose the terminologies as fresh in the current discipline of knowledge, there is no single definition that has gained universal acceptance. The World Bank defined e-Government in 2010 
as, "usage of information technologies by government agencies such as WANs, the internet and mobile computing that have the ability to interact with citizens, businesses and other arms of government". Ndou (2004) went furthered by classifying the major dimensions of e-Government as: e-administration (used for automation and the computerization of departmental administrative tasks); e-citizens (used to understand connections and interrelationships between governments and citizens); e-services (delivering automated services); and e-society (enabling relationships and interactions to take place beyond boundaries). There are three different domains of E-Government as proposed by Ndou (2004). These domains include E-society, Eadministration and E- services which all have overlapping domain.

\section{What is TAM Model}

The Theory of Reasoned Action was expanded and extended to present the Technology Acceptance Model. This was carried out by Davis (1989) to improve upon his earlier model. TAM explains the acceptance level of individual to information technology (Davis, 1989). The objective of TAM is providing a description of determinants of computer acceptance among the users. The two of the technology acceptance measures along with attitudes of TRA substituted TAM. Firstly, it is the perceived usefulness (PU) that denotes the rate of an individual believing to use a particular system that improves his/ her job performance. Secondly, ease of use (PEOU) denotes the rate at which an individual believes in utilizing a specific system that would be free from efforts (Davis, 1989). The TRA's subjective norms are not subjective to TAM determining BI. Figure 8 below presents the original theory behind TAM that comprises the attitude elements. On the basis of practical evidence, the concluding model excludes the attitude as it does not concentrate on the effect of PEOU intensively and $\mathrm{PU} \rightarrow \mathrm{BI}$ was regarded with much importance (Davis et al., 1989). The Theory of Acceptance Model assumes that PU is characterized by PEOU, as when others are equal, it makes easier to use technology. Compatible with TRA, TAM insists the effect of external variables to be resolved by PEOU and PU.

The model proposed by Davis et al., (1996) identified as Technology Acceptance Model. The model specified that actual use was dependent on the behavioural intention of an individual which was in turn impacted by the attitude towards usage. The two different attributes which determine the attitude towards usage were Perceived usefulness and Ease of use which is moderated by external factors.

\section{Research on E-services Using TAM Models}

The study evaluates well established models that are related to and explain the technology adoption. The chapter briefs and studies to a greater extent the Theory of Reasoned Action (TRA). According to the model, the performance of an individual on a specific behaviour is based on his or her behavioural intention (BI) for performing the behaviour. At the same time, an individual's attitude (A) and subjective norms (SN) are the factors determining the $\mathrm{BI}$ of an individual (Ajzen \& Fishbein, 1980).

Davis (1989) developed and formulated the Technology Acceptance Model (TAM) which is an expanded version of TRA. The model explains in detail the reasons for an individual accepting or declining the information systems. The theoretical basis of TRA was used by the TAM model. The three bases principle related to TAM is to clarify elements and aspects related to computer acceptance based on the perceived usefulness (PU) and ease of use (PEU) (Gefen \& Straaub, 2000). As can be seen in the figure above 2.8 which illustrates the TAM model, TAM is used to determine user acceptance of IS after exposure to the system for a short time period. An individual's acceptance of an information system is assessed by his/her intention to acknowledge and accept the technology. TAM is used in this study to establish a theoretical model to identify the factors affecting the acceptance of eservices. 


\section{E-service Modules in Dubai}

The department of e-governance have several synergistic services like Dubai.ae, mDubai, eLearn, Ask Dubai, ePay, eHost, eCitizen, eLibrary, eJob, eIntegration, and Web solution. The 'e' aspect of these functions helps it to reach a maximum part of the population of Dubai - citizens, residents, visitors, as well as businesses.

The DeG also works at the operational level in such a manner to create synergies while enabling generally used (shared) services. In this way, individual departments are able to concentrate on providing their core competency - eServices to people at large. Additionally, such synergistic services are provided to all the government bodies, which would benefit from them by way of reduced operational costs. This would also help them in enhancing their productivity quotient through faster and better implementation of timelines and effective utilization of resources.

Several benefits have been realized by the DeG through proper implementation of different synergies:

- Cost reduction: A penny saved is always a penny earned. The DeG has saved costs of about 37.1 million AED. In recent times, the savings have increased to about AED 70 millions and are now in the range of about $75 \%$ of the government services;

- Lesser time taken in conducting marketing initiatives for several governmental sections;

- Top quality benchmarks laid down for the different departments of the government;

- Sharing of ideal practices.

\section{Methodology}

This study has adopted a quantitative research approach. This research is said to have adapted case study research design since it is conducted with specific reference to a single entity: the General Directorate of
Residence and Foreigners Affairs of the United Arab Emirates. This research makes use of simple random sampling. The population of this research are the endusers (customers) of e-services or the public sector of the General Directorate Residency and Foreign Affairs (GDRFA). There were 466 people participating in the study. Three main purposes of research activity are found to be Exploratory, Descriptive and Explanatory (Saunders \& Lewis, 2000). In this study, the researchers adopted the explanatory research basis. This explanatory research basis identifies the explanation for the complex web of interconnected variables that have been obtained from the principal research questions. This will ensure that the research arrives at the solutions to the proposed problem.

A questionnaire was designed to be used as a main method for collecting data from the sample chosen for this study. A structured closed ended questionnaire was developed based on the previous literatures to identify adoption factors that impact the acceptance of e-services considering UAE context along with socio demographic factors. All the items of the study's questionnaire were adopted from previous studies and reliability and validity have been tested previously. The items that were used to measure each construct are: technical infrastructure, education and experience, ease of use, web skills, security, trust.

A questionnaire response was captured using a seven point Likert scale ranging from strongly disagree $=1$ to strongly agree $=7$. Hard copies were delivered to the end users by volunteer staff from the main GDRFA departments in Dubai; and a hard copy of the survey questionnaire was distributed around offices in each of the 7 Emirates. In the UAE, there are seven departments under GDRFA. The users of all the departments are offered e-services. In this research, these departments were the main focus of this study.

The questionnaire was pre-tested among the sample of respondents (not participated in the main study) before the 
main study to ensure reliability and validity of the data collected. The questionnaires were tested for identifying clarity in concept, correspondence to the subject matter, showing consistency with other questions, sufficient inclusive, correctness and accuracy, specificity and preciseness, a reasonable range of variations and finally items in each concept which is applied specifically to the topic.

\section{Data Analysis}

The responses collected from the respondents were carefully analysed, tabulated and interpreted so as to evaluate the level of awareness of respondents in respect to any enquiries the research may produce.

Descriptive analysis has been used as a statistical method with the percentage, frequency and the mean scale rating as an analytical factor. Here the status of government agent initiatives has been measured with frequency counts and percentage distribution. The level of acceptance as well as the level of completion of e-government initiatives has been expressed with respect to the mean scale. Also, the factors responsible for the successful e-transformation of electronic government and its impact on the UAE development are also measured with mean scales. Structural Equation Modelling (SEM) was used to analyse the survey data. The main purpose behind using this technique is to identify validity and reliability of each construct in the model.

\section{Demographics Analysis}

Table 1 shows the percentage of male and female respondents visiting the GDRFA. It can be observed from the results that around $60.0 \%$ of the participants were male and $39.3 \%$ were female. The annual data taken from the GDRFA revealed no significant difference in gender between the sample and the population. The gender distribution of the sample was similar to that of the annual data on clients visiting the GDRFA. The age of the participants is shown in Table 2 . Nearly $43 \%$ of the participants were in the age group of 26-
35 years. The respondents with the lowest levels of participation were aged above 60 years (4.5\%). Table 3 shows the nationality of the respondents who participated in the survey. It was observed that the highest percentage of respondents were of Asian origin (47.2\%) followed by African 13.5\% and Arabs: $13.5 \%$ for each nationality. The other nationalities were formed about 15\% of the respondents, whereas the Europeans were about 15\%. The annual data generated by the GDRFA also showed a similar trend where most of the visitors were of Asian origin. These results indicate that nearly $73 \%$ of the customers were from Asia, the Middle East and Africa. These characteristics of nationality can impact the acceptance and ease of use of the e-services. Research indicates that language can act as a principle barrier in the use of e-services (Al-Salih, 2004).

As indicated by these results, the first language of the majority of the customers is not English. As the e-services are provided in English, customers who are not able to correspond in English can have difficulty in using these services. The results also indicate that the number of female customers was comparatively much lower as compared to male customers. This relatively low percentage of female clients could be linked to the nationality of the respondents. A large percentage of the respondents are of Asian and African origin where due to cultural norms women are not as emancipated as in the west. The level of education is considered to be one of the most important pieces of demographic information. The importance of this aspect is that it may reflect the level of education of customers, which could indicate the Internet skills and self-efficacy that were adopted as essential constructs in the study model. Table 4 depicts the education level of the study sample. About $66 \%$ of the respondents had completed Secondary school education. Whereas, $29.8 \%$ were graduates and only $3.9 \%$ have a postgraduate degree. 
Table 1: Gender groups

\begin{tabular}{|l|l|}
\hline Gender & Percentage \\
\hline Male & 59.0 \\
\hline Female & 39.3 \\
\hline Total & 98.3 \\
\hline Missing & 1.7 \\
\hline Total & 100.0 \\
\hline
\end{tabular}

Table 2: Age groups

\begin{tabular}{|l|l|}
\hline Age & Percentage \\
\hline $18-25$ & 23.8 \\
\hline $26-35$ & 42.9 \\
\hline $36-45$ & 22.3 \\
\hline $46-60$ & 6.4 \\
\hline Above 60 & 4.5 \\
\hline Total & 100.0 \\
\hline
\end{tabular}

Table3: Nationality groups

\begin{tabular}{|l|c|}
\hline Nationality & Percentage \\
\hline UAE & 0.6 \\
\hline Arab & 13.5 \\
\hline European & 10.1 \\
\hline Asian & 47.2 \\
\hline African & 13.5 \\
\hline Others & 15.0 \\
\hline Total & 100.0 \\
\hline
\end{tabular}


Table 4: Education level

\begin{tabular}{|l|c|}
\hline Education & Percent \\
\hline $\begin{array}{l}\text { Sec. school } \\
\text { Certificate }\end{array}$ & 33.0 \\
\hline Unfinished Grad. & 33.3 \\
\hline College Graduates & 29.8 \\
\hline Post Graduate & 3.9 \\
\hline Total & 100.0 \\
\hline
\end{tabular}

\section{Quantitative Descriptive Analysis}

In general, the GDRFA offers two types of services either online or paper-based services using typing centers. Not all department services are available through online mode. The customers get to choose the type of service based on their personal preferences. Describing the items and constructs used in this study, it is necessary to identify the general trend of customers who participated in this study toward these constructs and items. All 5 constructs with 23 items selected to examine the factors that impact the acceptance of online services in the GDRFA are described in this section. At this stage each of them is described separately to find out the perceptions of the respondents towards the items in these constructs. The constructs include: ease of use, language, web skills, security, and trust.

Ease of use of the electronic system in the GDRFA was selected as an essential construct to identify factors affecting the acceptance of electronic services. This construct was used by Davis (1989) as a main construct to establish TAM. Eight items were used to measure ease of use of the GDRFA online system. The items indicating ease of use, as shown in Table 5, had mean scores above 5 . These results show that the respondents using the GDRFA service found the online service much easier to use because it required less effort and was uncomplicated as there was less chance of making errors and more chance to recover from errors while using the service. 
Table 5: Descriptive statistics of ease of use

\begin{tabular}{|l|l|l|l|l|l|}
\hline \multicolumn{1}{|c|}{ Item } & N & Min & Max & Mean & SD \\
\hline $\begin{array}{l}\text { I make less error when I use the GDRFA online } \\
\text { service }\end{array}$ & 466 & 1 & 7 & 5.55 & 1.523 \\
\hline $\begin{array}{l}\text { I do not need to consult the user manual when using } \\
\text { the GDRFA online services }\end{array}$ & 466 & 1 & 7 & 5.24 & 1.513 \\
\hline $\begin{array}{l}\text { Interacting with the GDRFA online services } \\
\text { requires less mental effort. }\end{array}$ & 466 & 1 & 7 & 5.56 & 1.562 \\
\hline $\begin{array}{l}\text { I find it easy to recover from errors encountered } \\
\text { while using GDRFA online services }\end{array}$ & 466 & 1 & 7 & 5.31 & 1.542 \\
\hline $\begin{array}{l}\text { I find it easy to use the GDRFA online services to } \\
\text { do what transactions I need }\end{array}$ & 466 & 1 & 7 & 5.15 & 1.523 \\
\hline It is easy to navigate around GDRFA site & 466 & 1 & 7 & 5.49 & 1.544 \\
\hline $\begin{array}{l}\text { The GDRFA online services provide helpful } \\
\text { guidance in performing tasks }\end{array}$ & 466 & 1 & 7 & 5.23 & 1.587 \\
\hline Overall, I find the GDRFA e-services easy to use & 466 & 1 & 7 & 5.33 & 1.444 \\
\hline Total mean score & & & & $\mathbf{5 . 3 5}$ & \\
\hline
\end{tabular}

According to the study model, language is considered one of the most important factors that affect the acceptance of eservices. Based on this assumption, language is a determinant of the intention to adopt the e-services of the GDRFA. This construct was measured using four items.
The mean scores of the items determining Language ranged between 4.64-4.42 as shown in Table 6 . These scores indicate that the respondents moderately agreed that language did not hamper their use of the GDRFA and it provided sufficient language facilities to its clients

Table 6: Descriptive statistics of language

\begin{tabular}{|l|l|l|l|l|l|}
\hline \multicolumn{1}{|c|}{ Item } & N & Min & Max & Mean & SD \\
\hline $\begin{array}{l}\text { I could complete the GDRFA online services without online } \\
\text { transaction }\end{array}$ & 466 & 1 & 7 & 4.47 & 1.849 \\
\hline $\begin{array}{l}\text { I can complete the GDRFA online services without the help } \\
\text { of Arabic speaking translator }\end{array}$ & 466 & 1 & 7 & 4.63 & 1.716 \\
\hline $\begin{array}{l}\text { Language is not a key barrier for me to use GDRFA online } \\
\text { services }\end{array}$ & 466 & 1 & 7 & 4.64 & 1.826 \\
\hline GDRFA provides sufficient language facilities its clients & 466 & 1 & 7 & 4.42 & 1.863 \\
\hline Total mean score & & & & $\mathbf{4 . 5 4}$ & \\
\hline
\end{tabular}

Web skills is one of the most important constructs selected to establish the study model. This construct has been used to identify the skills of users to use websites and specifically the GDRFA web site. Four items were employed to measure this construct. Table 7 shows the mean scores of items determining web skills. Item, "I am very skilled at using the GDRFA website," had the highest mean value of 5.66, indicating that the users of GDRFA had moderately high web skills. The results also indicate that respondents were comfortable with using Internet service, as they were familiar with it. 
Table 7: Descriptive statistics of web skills

\begin{tabular}{|l|l|l|l|l|l|}
\hline \multicolumn{1}{|c|}{ Item } & N & Min & Max & Mean & SD \\
\hline I am very skilled at using the GDRFA website & 466 & 1 & 7 & 5.66 & 1.734 \\
\hline I know how to find what I want on the GDRFA website & 466 & 1 & 7 & 5.49 & 1.577 \\
\hline $\begin{array}{l}\text { I know more about using the GDRFA website than most my } \\
\text { colleagues }\end{array}$ & 466 & 1 & 7 & 5.44 & 1.572 \\
\hline I have experience to deal with complicated websites & 466 & 1 & 7 & 5.50 & 1.639 \\
\hline Total mean score & & & & $\mathbf{5 . 5 2}$ & \\
\hline
\end{tabular}

Security is considered to be one of the most important issues confronting organisations and customers in the online commerce and services. This issue should take into account the acceptance of electronic systems. Based on that, this construct has been included in the study model as an essential construct, which has impacted the acceptance of the GDRFA online services.
The mean values of items of Security were above 5 . The result shows in table 8 that the respondents felt reasonably secure in providing personal information. They felt that the GDRFA, to some extent, protected their personal information. Therefore, the risks in doing online transactions with the GDRFA could be considered moderately low.

Table 8: Descriptive Statistics of security

\begin{tabular}{|l|l|l|l|l|l|}
\hline \multicolumn{1}{|c|}{ Item } & N & Min & Max & Mean & SD \\
\hline $\begin{array}{l}\text { I feel secure in providing personal } \\
\text { information for GDRFA online services }\end{array}$ & 466 & 1 & 7 & 5.27 & 1.645 \\
\hline $\begin{array}{l}\text { I feel the risk associated with GDRFA } \\
\text { transactions is low }\end{array}$ & 466 & 1 & 7 & 5.26 & 1.669 \\
\hline $\begin{array}{l}\text { GDRFA website does not share my personal } \\
\text { information with other sites }\end{array}$ & 466 & 1 & 7 & 5.19 & 1.562 \\
\hline $\begin{array}{l}\text { GDRFA website protects information about } \\
\text { my credit card }\end{array}$ & 466 & 1 & 7 & 5.22 & 1.595 \\
\hline Total mean score & & & & $\mathbf{5 . 2 3}$ & \\
\hline
\end{tabular}

Trust between the service provider (government) and the service requester (citizens and businesses) is considered to an important construct that influences egovernment adoption (Al-Sobhi, Weerakkody, Mustafa, \& Kamal 2010). Based on the importance of this construct in the acceptance of online services, it was selected to be a part of the study model. Five items were used to measure this construct. The items describing trust are shown in table 9. The scores on trust ranged between 4.41 and 4.26. These results indicate that the clients' trust in the services provided by the GDRFA was not high. The main reason could be the problems facing clients while following the procedures involved during the transaction. Online transactions could take a long time to process the information fed into it maybe because of the lack of customers' support, the speed of the Internet connections and the lack of adequate resources to handle the number of users. 
Table 9: Descriptive statistics of trust

\begin{tabular}{|l|l|l|l|l|l|}
\hline \multicolumn{1}{|c|}{ Item } & N & Min & Max & Mean & SD \\
\hline $\begin{array}{l}\text { Based on my experience with GDRFA } \\
\text { online services, I know it is honest }\end{array}$ & 466 & 1 & 7 & 4.26 & 1.865 \\
\hline $\begin{array}{l}\text { Based on my experience with GDRFA } \\
\text { online services, I know it cares about } \\
\text { customers. }\end{array}$ & & 166 & 7 & 4.41 & 1.778 \\
\hline $\begin{array}{l}\text { Based on my experience with GDRFA } \\
\text { online services, I know it provides good } \\
\text { service. }\end{array}$ & 466 & 1 & 7 & 4.38 & 1.817 \\
\hline $\begin{array}{l}\text { Based on my experience with GDRFA } \\
\text { online services, I know it is trustworthy }\end{array}$ & 466 & 1 & 7 & 4.27 & 1.805 \\
\hline $\begin{array}{l}\text { Based on my experience with GDRFA } \\
\text { online services, I know it is not } \\
\text { opportunistic }\end{array}$ & & 166 & 7 & 4.38 & 1.740 \\
\hline Total mean score & & & & $\mathbf{4 . 3 4}$ & \\
\hline
\end{tabular}

The total mean scores of each of the ten constructs indicated that the customers' responses for constructs: "ease of use" $(\mathrm{m}=5.35)$ and "web skills" (5.25) were the highest. These results demonstrate that the customers had sufficient web skills and indicated good knowledge of using the Internet and computer based on-line programs. On the other hand, the respondents exhibited the lowest mean scores for "trust" (4.34) and "language" (4.54). These results indicate that the customers were not that satisfied with the service providers' support and performance in building a relationship of trust with the customers. This result indicates that the GDRFA online services would require improvement to increase the level of trust and support to facilitate the customers' satisfaction. The language was also a barrier to accomplish the online transactions with ease by the customers.

An ANOVA test was used to analyse the difference in the respondents' perceptions towards the constructs of the study model. Based on the education criteria, the sample was divided into two categories: secondary and unable to finish college" and "graduate and post graduate". The ANOVA analysis shows that there are no significant statistical differences at level 0.05 between the perceptions of respondents according to education level "secondary and unable to finish college" and "graduate and post graduate". Accordingly, the perception of respondents toward the ten constructs of the study model shows no difference according to the variations in the educational level of the customers. Through the use of ANOVA, an analysis was conducted based on the nationalities of participants to identify the differences in perceptions towards the study model constructs. The results of ANOVA show that the no difference was found in the perceptions of participants toward four constructs: ease of use; web skills, security; and trust. The values of these constructs were between 0.221 and 1.842 and all these values were not significant. However, there is a difference between the participants based on nationality toward "language" construct. The differences towards the language construct were between the Arab and Asian and Arab and African. The essential reason behind these differences is that the web-site of the GDRFA is available with Arabic and English languages and does not support Asian and African languages. 


\section{Discussion}

The primary objective of this study is to investigate and identify the perceptions of potential end users relating to factors which impact on e-services acceptance. Secondly, this research validates the developed TAM model and evaluates the variance of the outcome variable (acceptance of e-services). Since TAM has been adopted in this study as it can be extended when technologies are introduced (Shih, 2003).

The study adopted a quantitative survey methodology, whereby 466 customers who visited the web pages of government departments to obtain information and use the e-services became the study's respondents. To our knowledge, this is the first study to examine the relationship of the electronic service usage utilizing the TAM model and e-service adoption using the SEM model in the UAE. The overall findings revealed that security, language, web skills and support significantly affected ease of use and perceived usefulness. However, trust and computer self-efficacy did not affect ease of use. Further, ease of use significantly affected intention to use and perceived usefulness; while in turn, intention to use was influenced by perceived usefulness. The results and model developed within this study,corroborate the previous study findings (theories) of Venkatesh et al., (2000, p.187) and Davis (1989) that perceived usefulness and ease of use affect a person's intention to use the technology (in this case e-government system), which in turn affect the usage behaviour. It was also shown through this study that validity and reliability of TAM has been confirmed and proved. The model included in the TAM research model is Trust, Support, Security, language, web skills, computer self-efficacy and marketing mix.

The study had failed to show any significant association between adoption of perceptions and education level and nationality. However, significant differences were observed for certain adoption factors such as e-marketing, selfefficacy and support where Asian ranked higher compared to other nationalities. This may be due to the higher sample size in the Asian group compared to those of Arab origin. Regarding the intention to use the GDRFA online system, the differences were between Asian and European and others, and Asian and African. The main justification to these differences is that most of the Asian population intend to stay in the UAE for work purposes; however the African, European and others may visit the UAE for short visits. The findings of the study also revealed e-marketing was ranked by Asians. These findings are in line with the report of the GDRFA, where the numbers of people who visit the UAE are from Asia and use the facilities to try to renew their visas to stay for longer periods of time. The Asian population may pay more attention to e-marketing elements to collect information about the types of visa, fees, channels used for visa applications, and the updated information about visa regulations.

The differences towards the language construct were between the Arab and Asian and Arab and African. The essential reason behind these differences is that the web-site of the GDRFA is available with Arabic and English languages and does not support Asian and African languages. Finally, the differences towards support construct were between the European and others and Asian, and European and others and African. The differences in the support construct may be due to the language barriers or the differences in the experiences to deal with the GDRFA online systems. As noticed, the age of customers, the educational qualifications and computer knowledge has little influence on customers' intent to utilize e-Government public facilities in the UAE. This finding is in contrast to certain research papers that reiterate the significance of the digital divide and awareness in utilizing computers and the Internet as obstacles for utilizing e-Government facilities (Chadwick \& May 2003; Cartar \& Belanger, 2005). In the instance of the UAE, it is possible that the information available in the Global Information Technology Report 20102011 has identified that ninety percent of the populace has knowledge of computer 
usage and the Internet. The findings may further reveal that the impact of demographic variables over customers' intent to utilize e-Government facilities varies from nation to nation and there is immense scope for investigation in this field.

Based on the results of the study, gender and education levels of users have a significant role in carrying out transactions and for gathering information using egovernment. The result is also concurrent with the findings of Van Dijk et al. (2008), on the claim that the social demographic and psychological factors do not have an influencing effect on the usage and acceptance factors of e-government. Also, previous exposure to the computers or the Internet does not have an influence on the usage and transactions of the egovernment. It is very surprising that this kind of result is obtained while taking into account that most of the respondents have a good profile with respect to the Internet and computer usage. The future research prospects can include other parameters such as income level, place of residence, marital status, profession, etc. The future focus of the decision and policy makers would be to increase the awareness of egovernment services with different groups of the community.

Several factors derived from the Technology Acceptance Model (TAM) have been used in order to successfully obtain acceptance of e-services of the General Directorate of Residency and Foreigners Affairs in the UAE. Firstly, the study validated the TAM constructs in a developing country context and is the first of its study in the UAE. Secondly, the TAM constructs have identified different factors that influence e-government usage and this study contributed to the existing literature by adding and testing extra untested constructs such as web-skills, ease of use and particularly trust which is considered as an important factor to reach customers. This construct includes factors which deal with how users perceive the use of online services according to cultural norms and values. Thirdly, the study was conducted with a large sample size $(n=466)$, and as has been ascertained this is the first study to be conducted with such a large sample size which concentrates on the seven Emirates of the UAE. Finally, the findings revealed that security, language, web and computer skills and support significantly affected ease of use and perceived usefulness. However, trust and security do not affect ease of use.

\section{Conclusion}

This is one of the several national level research studies to understand and explore the challenges faced by the customers' "adoption of e-government services" in the UAE. The research study provides empirical evidence to show that wider adoption of e-services and obtaining their benefits such as convenience of use and prompt services in comparison with conventional means of service would probably spread the usage throughout the UAE. The complete potential of egovernment services cannot be tapped if a large population of customers do not participate in the adoption and utilization of the service. This fact is evident from the UAE government's plans and efforts to further e-government development and disseminate the same among the customers throughout the seven Emirates of the UAE to ensure the ease of acquiring and providing services. Nevertheless, the challenges delineated in the research show that these objectives are practically more complicated than conceived. Therefore, measures should be taken to mitigate the challenges rather than to fully resolve them. Similarly, from the view point of the user, a number of previous studies display various factors that are considered to be significantly influential in comprehending customers' decision making in adopting eservices from a national perspective. The initial steps taken by the UAE government to propagate e-government services to the wider public have been successful and this is a motivating outcome for all stakeholders' (government, enterprises, and customers) further developments.

The government can introduce stronger measures to further promote the UAE egovernment website while also taking 
appropriate steps to assist the less computer savvy customers by setting up customer service centres. These observations in the practical sense are encouraging for the major part; however, in a theoretical sense, these findings acknowledge that acceptance of technology is important for its success and the acceptance depends on key aspects like: trust, language, support, web skills, and security. However, the practical view point still remains that although the results obtained from the present analysis are positive, the concept of e-government has yet to mature to a state of attaining success. It is clear from various empirical studies that this state is not yet reached primarily due to customers' concerns about security and lack of uniformity of access to Internet access. It can therefore be concluded that to implement e-government in the UAE successfully it requires for the government to fully understand the needs of the customers and apprehensions in terms of security and take measures to amend factors of concern associated with egovernment adoption.

The study also developed various recommendations for future improvement, which include the followings:

- More attention should be paid to the elements of marketing mix

\section{References}

1. Ajzen, I. and Fishbein, M.(1980) Understanding attitudes and predicting social behavior, Englewood Cliffs NY : Prentice Hall, http://www.amazon.com/UnderstandingAttitudes-Predicting-SocialBehavior/dp/0139364358

2. Al-Salih, Y. N. (2004). Graduate students' information needs from electronic information resources in Saudi Arabia, Unpublished doctoral dissertation, Florida State University, Florida, etd.lib.fsu.edu/theses/available/etd07092004-164418/.

3. Carter, L. and Belanger, F. (2005) 'The utilisation of egovernment services: citizen trust innovation and acceptance factors', such as products, promotion, price, and distribution of electronic services.

- $\quad$ The website of the GDRFA should be offered in different languages such as Indian and Chinese languages. The main reason behind this suggestion is that most users of e-services are from Asia.

- The support should not be limited to technical support but should also include language support by providing the customers with services of translation due to the variety of nationalities of the GDRFA customers.

- The instructions to the electronic payment system should be clear. The users may not trust the electronic payment because no specific instructions are provided to them about the payment.

- Support the current systems with new complementary software to enhance trust and security of the electronic system of the GDRFA.

- The study revealed that there are other factors that affect the customers' acceptance of the GDRFA services which could be a subject of future study.

Information Systems Journal, 15(1), pp.525, http://onlinelibrary.wiley.com/doi/10.111 1/i.1365-2575.2005.00183.x/abstract

4. Chadwick, A. and May, C. (2003) 'Interaction Between States and Citizens in the Age of the Internet: "E-Government" in the United States, Britain and the European Union', Governance, 16(2), pp. 271- 300, http://onlinelibrary.wiley.com/doi/10.111 $1 / 1468-0491.00216 / \mathrm{pdf}$.

5. Davis F.D. (1989) 'Perceived Usefulness, Ease of use, and User Acceptance of Information Technology', MIS Quarterly, 13(2), pp. 319-339, www.jstor.org/stable/249008.

6. Davis F. D., Bagozzi, R. P and Warshaw, P. R.(1989) 'User acceptance of computer 
technology: A comparison of two theoretical models', Management Science, 35(8), pp. 982-1002, pubsonline.informs.org/doi/abs/10.1287/ mnsc.35.8.982.

7. Davis, F., \& Venkatesh, V. (1996) 'A critical assessment of potential measurement biases in the technology acceptance model: three experiments', International Journal of Human Computer Studies, 45(1), pp. 19-45, www.sciencedirect.com/science/article/pii /S1071581996900403.

8. Featherman, M. S. ans Pavlou, P. A.(2003) 'Predicting e-services adoption: a perceived risk facets perspective', International Journal of Human-Computer Studies, 59(4), pp. 451-74, sighci.org/amcis02/CR/Featherman.pdf.

9. Gefen, D. and Straub, D. W. (2000) 'The Relative Importance of Perceived Ease-ofUse in IS Adoption: A Study of E-Commerce Adoption', Journal of the Association for Information Systems, 1(8), pp. 1-30, www.cis.gsu.edu/dstraub/Courses/.../TimMathieu-Betrice\%20choice.pdf.

10. Ghosh, S. (2009) 'Application of natural language processing (NLP) techniques in egovernment', Information Science Reference, New York, citeseerx.ist.psu.edu/viewdoc/summary?d $\mathrm{oi}=10.1 .1 .97 .257$.

11. NDOU, V. (2004) 'E-government for developing countries: Opportunities and challenges', EJISDC, 18(1), pp. 1-24, unpan1.un.org/intradoc/groups/public/do cuments/.../unpan018634.pdf.

12. Saunders, M. and Lewis, P. (2000) Research Methods for Business Students, $2^{\text {nd }}$ edn., Financial Times, London: Prentice Hall, http://www.amazon.co.uk/ResearchMethods-Business-StudentsSaunders/dp/0273716867.

13. Shih, H. (2003) 'Extended technology acceptance model of Internet utilization behaviour, Information \& Management, 41(6), www.sciencedirect.com/science/article/pii /S0378720603001216.

14. Reddick, C. G.(2006) 'Information resource managers and e-government effectiveness: A survey of Texas state agencies', Government Information Quarterly, 230, pp. 249-266, www.sciencedirect.com/science/article/pii /S0740624X0500095X.

15. Venkatesh, V. and Davis, F.D.(2000) 'A Theoretical Extension of the Technology Acceptance Model: Four Longitudinal Field Studies', Management Science, 45(2), pp. 186-204 www.jstor.org/stable/2634758.

16. Yildiz, M. (2007) 'E-government research: Reviewing the literature, limitations, and ways forward', Government Information Quarterly, pp. 546-665, www.sciencedirect.com/science/article/pii /S0740624X07000056.

17. Zhao., Annibal, F. J., Scavarda and Waxin, M. (2012) 'Key issues and challenges in e-government development: An integrative case study of the number one eCity in the Arab World', Information Technology \& People, 25(4), http://www.academia.edu/3757052/Key i ssues and challenges in egovernment development An integrative c ase study of the number one eCity in the Arab world 